\section{Radioiodo Como Terapia Adjuvante em Pacientes com Carcinoma Medular de Tiveóide}

C Télulas parafoliculares, que originam o carcinoma medular de tireóide (CMT), não captam iodo. No entanto, as células residuais em leito tireoideano após a tireoidectomia encontram-se em proximidade com células foliculares normais, iodocaptantes. Isto, somado ao alcance de $2 \mathrm{~mm}$ da radiação beta, fundamentam a idéia de "radiação por contiguidade" para o CMT residual ou recorrente em leito tireoideano. As células foliculares normais captam o iodo 131 (I-131) e a radiação beta emitida alcançaria as células parafoliculares malignas próximas.

Relato um caso que atendi, procedente de outro serviço de uma cidade do interior, para continuar o acompanhamento. Trata-se de uma paciente de 52 anos, que tinha um nódulo único à palpação de $3,5 \mathrm{~cm}$ em lobo direito da tireóide, e a PAAF mostrou CMT. Foi submetida à tireoidectomia total com esvaziamento ganglionar cervical e o anatomopatológico confirmou o diagnóstico de CMT com metástases linfonodais. A imuno-histoquímica foi positiva para calcitonina (CT) e negativa para tireoglobulina (Tg). A CT sérica pré-operatória era de $642 \mathrm{pg} / \mathrm{ml}$. Seis meses após a cirurgia, permanecia elevada $(890 \mathrm{pg} / \mathrm{ml})$, mas o exame clínico e métodos de imagem não revelaram metástases. US cervical, TC de tórax e abdome, pesquisa de corpo inteiro (PCI) com 99mTc-Sestamibi e 201-Tl (tálio) foram normais. Não foram realizadas imagens com $99 \mathrm{mTc}-\mathrm{DMSA}$ pentavalente ou Octreotide. A PCI com I-131 mostrou uma captação em leito tireoideano de $2,5 \%$. Dois meses depois, a paciente foi submetida à radioiodoterapia com $150 \mathrm{mCi}$ e a PCI pós-dose confirmou o achado do exame anterior. Com 3, 6, 9 e 12 meses (aproximadamente) depois do radioiodo, os níveis de CT não apresentaram queda: 786, 976, 1033, $875 \mathrm{pg} / \mathrm{ml}$, respectivamente. A repetição da mesma propedêutica um ano depois da terapia ablativa, quando a paciente passou a ser acompanhada por mim, permaneceu não revelando metástases, e a PCI com I-131 foi negativa, inclusive para restos tireoideanos.

Apesar da proximidade das células foliculares normais com os focos de carcinoma medular que podem permanecer em leito tireoideano após a tireoidectomia, ser suficiente para que a radiação beta alcance por contigüidade estes focos, a radioiodoterapia não tem demonstrado resultado em pacientes com CMT puro, como neste caso. Resultados favoráveis são apresentados apenas como casos isolados $(1,2)$ ou no carcinoma misto medular-folicular (3), que pode ser erroneamente diagnosticado como medular puro; não havendo estudos comparativos (entre tratados e não tratados) que confirmem o benefício do radioiodo no CMT puro. Ao contrário, os estudos mostram que não há diferença na taxa de recorrência, no aparecimento de metástases e na mortalidade entre pacientes tratados ou não com radioiodoterapia pós-operatória (4-6), que também não se mostrou eficaz em reduzir os níveis séricos de CT $(4,7)$. Um possível benefício na taxa de recorrência nos casos sem hipercalcitoninemia pós-operatória sugerido por um destes estudos (7) pode ser contestado pelo curto tempo de seguimento ( 2 anos) e pela ausência de comparação com

\section{cartas ao editor}

\author{
Pedro Weslley S. Rosário \\ Tales Alvarenga Fagundes
}

INAL Ciências e Saúde, Belo Horizonte, $M G$. 
pacientes que não receberam radioiodo. Assim, pela falta de dados convincentes e seguindo a recomendação dos principais guidelines sobre o tema, que não colocam o radioiodo como terapia adjuvante para este tipo de tumor (8-10), não defendemos a adoção deste tratamento no CMT puro.

Uma situação especial seria o carcinoma misto medular-folicular (3). Neste, na presença de captação de I-131 na PCI, o tratamento com radioiodo deve ser tentado, e, provavelmente, muitos casos com captação de iodo representem este tipo de tumor e não CMT puro. Existem relatos de CMT considerados puros com metástases iodocaptantes (11), mas a raridade destes casos não justifica a realização de PCI com iodo 131 em pacientes com CMT.

\section{REFERÊNCIAS}

1. Deftos LJ, Stein MF. Radioiodine as an adjunct to the surgical treatment of medullary thyroid carcinoma. J Clin Endocrinol Metab 1980;50:967-8.

2. Hellman DE, Katchner M, van Antwerp JD, Salmon SE, Patton DD, O'Mara R. Radioiodine in the treatment of medullary carcinoma of the thyroid. J Clin Endocrinol Metab 1979;48:451-5.

3. Papotti M, Volante $M$, Komminoth $P$, Sobrinho-Simões $M$, Bussolati $G$. Thyroid carcinomas with mixed follicular and C-cell differentiation patterns. Semin Diagn Pathol 2000;17:109-19.

4. Saad MF, Guido JJ, Samaan NA. Radioactive iodine in the treatment of medullary carcinoma of the thyroid. $\mathbf{J}$ Clin Endocrinol Metab 1983;57:124-8.
5. Saad MF, Ordonez NG, Rashid RK, Guido JJ, Hill CS Jr, Hickey RC, et al. Medullary carcinoma of the thyroid. A study of the clinical features and prognostic factors in 161 patients. Medicine (Baltimore) 1984;63:319-42.

6. Dottorini ME, Assi A, Sironi M, Sangalli G, Spreafico G, Colombo L. Multivariate analysis of patients with medullary thyroid carcinoma. Prognostic significance and impact on treatment of clinical and pathologic variables. Cancer 1996;77:1556-65.

7. Nieuwenhuijzen Kruseman AC, Bussemaker JK, Frolich $M$. Radioiodine in the treatment of hereditary medullary carcinoma of the thyroid. J Clin Endocrinol Metab 1984;59:491-4.

8. AACE-AAES medical-surgical guidelines for clinical practice: management of thyroid carcinoma. Endocr Pract 2001;7:202-20.

9. Mazzaferri EL. 1999 NCCN thyroid carcinoma practice guidelines. Oncology 1999;13 (Suppl 11A): 391-442. http://www.ncen.org

10. British Thyroid Association. Guidelines for the management of differentiated thyroid cancer in adults. http://www.british-thyroid-association.org

11. Michael BE, Forouhar FA, Spencer RP. Medullary thyroid carcinoma with radioiodide transport. Effects of iodine131 therapy and lithium administration. Clin Nucl Med 1985; 10:274-9.

\section{Endereço para correspondência:}

Pedro Weslley Souza Rosário

Rua Grão Pará 304 - 903

30150-340 Belo Horizonte, MG

E-mail: pedrorosario@globo.com 